Three cases were reported last year, and I here present another case, the youngest yet on record, the patient being only 13 days old at death.

\section{History OF the CASE}

A male baby, born on September 19th, 1930, was admitted on October 1st on account of haemoptysis. He was a fulltime baby, and only weighed 2,950 grams, and had been fed on Nestlé's milk, supplementary to the breast. When admitted he was slightly cyanosed, and twenty hours after admission had a profuse nasal haemorrhage of bright red and frothy blood, and died almost immediately (October 2nd).

The post-mortem findings were as follows. The urachus contained a little pus just within the umbilicus. The trachea and bronchi contained frothy blood, the lining walls being normal. The lower lobes of both lungs showed numerous peripheral areas of consolidation, dark red, almost black, well defined, and raised above the surface of the aerated lung. The upper lobes were aerated, but had a few discrete areassimilar to those found in the lower lobes-much smaller and more clearly defined. These were undoubtedly small infarctions, but the actual source of the terminal haemorrhage was not discovered. An area of endocarditis was discovered on the posterior wall of the right ventricle, about $1 / 4$ inch proximal to the pulmonary valve. This area, $3 / 4$ inch by $1 / 8$ inch, consisted of dark-coloured fibrinous exudate, which stripped easily from the endocardium, leaving a roughened surface. The heart valves were normal.

\section{RAPID LABORATORY TEST FOR PREGNANCY}

\author{
BY
}

GLADYS H. DODDS, M.D., D.P.H.

ASSISTANT IN THE OBSTETRIC UNIT, UNIVERSITY COLLEGE HOSPITAL

During the last few years, and particularly since the introduction into general use of the Zondek-Aschheim test for pregnancy, numerous investigators have attempted to find a test which is as reliable and which would give more rapid results. The great advantage of rapid diagnosis in cases of ectopic gestation or fibroids and pregnancy is obvious.

Zondek and Aschheim ${ }^{1}$ showed that the urine of pregnant women contained a substance which produced certain characteristic changes-namely, corpora haemorrhagica and corpora lutea-in the ovaries of the immature female mouse. They also showed that, with few exceptions, this ovary-stimulating substance was peculiar to the urine of pregnancy. Friedman, ${ }^{2}$ in 1929 , appears to have been the first to have studied the mechanism of ovulation of the rabbit by injection of urine of pregnant women. He showed the advantage of using the rabbit instead of the mouse to test for substances which produce ovulation. In the rabbit, ovulation ${ }^{3}$ does not occur until the age of 5 months in the summer and 6 to 8 months in the winter ; ovulation is dependent on copulation, and following copulation ovulation occurs in eight to ten hours. Ovulation is easily recognized by inspection of the ovaries; either fresh corpora lutea or projecting corpora haemorrhagica can be seen on the surface. In a series of twenty-two rabbits in which Friedman had injected $5 \mathrm{c} . \mathrm{cm}$. of urine intravenously, positive results were obtained from the urine of eighteen pregnant, and negative results from the urine of fourteen non-pregnant, women. Nine of the positive results were noted twenty-four hours after the injection. Friedman suggested that the test might be useful in the diagnosis of pregnancy.

Adèle Brouha, ${ }^{4}$ in the early part of this year, described a similar test for pregnancy. She used virgin rabbits weighing about 1 kilogram, and, with a single intravenous injection of urine, obtained results in fifteen to twenty-
The microscopical examination of the fibrinous material loosely attached to the endocardium below the pulmonary valve had the appearance of acellular decolorized clot deposited from the moving blood stream. In sections stained for bacteria staphylococci were present in large numbers. There was no microscopical evidence of disease of the heart muscles.

\section{Conclusions}

The appearances in the upper lobes of the lung were due to pulmonary infarction, and in the lower lobes to insufflations of blood. The primary focus was the septic condition of the cord, followed by a secondary infective (staphylococcal) endocarditis, which gave rise to multiple pulmonary infarction.

H. Kornfeld, 1905.

Appended is a list of references to previously reported cases, for which I am indebted to the Líbrarian of the British Medical Association.

Von Dusch, T.: In Gerhardt; Handbuch der Kinderkrankheiten, Tübingen, 1878, iv, 324

Steffen, A.: Klinik der Kinderkrankheiten, Berlin, A. Hirschwald, 1889, iii.

Blum, S.: Centralbl. f. Bakteriol. u. Parasitenk., 1899, xxv, 113.

Lempp, K.: Monatsschr. f. Kinderheilk., 1907, vi, 78.

Dean, H. R.: Brit. Journ. Child. Dis., 1912, ix, 317

Dible, J. H.: Journ. Path. and Bact., 1920; xxiii, 196.

Skinner, E. F.: Lancet, 1922, i, 1147.

Sansby and Larson: Amer. Journ. Dis. Child., June, 1930, 1261

Alfreda, Loffredo: Pediatria, March 15th, 1930, xxxviii, 311

four hours. Brouha ${ }^{5}$ carried out the test in nearly two hundred cases in which the diagnosis was in doubt, and in each case the laboratory findings agreed with the clinical.

Reinhart and Scott, ${ }^{6}$ Schneider, ${ }^{7}$ Magath and Randall, ${ }^{8}$ and Friedman and Lapham ${ }^{9}$ have used a similar method for the diagnosis of pregnancy. Their techniques varied, but their results have been as good as those of the Zondek-Aschheim test. Reinhart and Scott used adult female non-pregnant rabbits weighing not less than $4 \mathrm{lb}$.; they gave a single injection, and obtained results in twenty-four hours; in a series of fifty cases they had only one error. Schneider used female rabbits, aged 12 to 14 weeks; he gave a single injection, and obtained results in twelve to twenty-four hours ; in a series of one hundred cases there were two errors, and in these two the technique was faulty. Schneider recommends the use of two rabbits in cases of urgency, as in some cases a result may be obtained in twelve hours, which may be confirmed later in another twelve hours. Magath and Randall used female rabbits over $2 \frac{1}{2}$ months old ; they gave a single injection, and obtained results in thirty hours ; in a series of eighty-five cases they had two errors. Friedman and Lapham used unmated mature female rabbits. The urine was injected thrice daily for two days in $4 \mathrm{c} . \mathrm{cm}$. doses. Forty-eight hours after the first injection the rabbit was killed. Before they adopted this routine Friedman and Lapham used the single injection, with post-mortem eighteen hours later; but they found that it was not entirely reliable, although in case of urgency it could be used if too much reliance was not placed on negative results.

\section{Technigue and Results}

The rapidity and reliability of the test, according to these observers, suggested its use to us, and we consider that the results in a small series of fifty-three cases investigated at University College Hospital worthy of record.

The technique used in the first twenty cases was that of Adèle Brouha. A single intravenous injection of 8 to $12 \mathrm{c.cm}$. of urine was given to virgin rabbits weighing about 1 kilogram, and a post-mortem was done fifteen to twenty-four hours later. Urine from seventeen pregnant and three non-pregnant women was investigated; 
there were six errors ( 30 per cent.), all in the pregnant group. The period of pregnancy in the cases investigated was from six to fourteen weeks, a period during which the test is most useful. There were two cases of hydatidiform mole, and each gave a positive result. The technique adopted in the remaining thirty-three cases was as follows. Virgin rabbits, aged 12 to 20 weeks, were used, and two injections of $6 \mathrm{c.cm}$. were given intravenously for two days. Forty-eight hours after the first

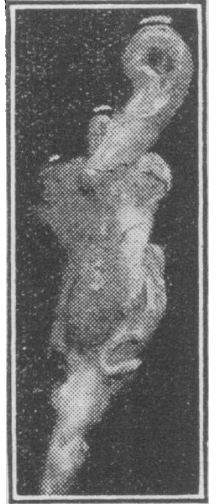

Fig. 1.-Ovary of 12-weeksold rabbit, which hat been injected with urine from a non-pregnant woman. $\left(\times 1 \frac{3}{4}.\right)$

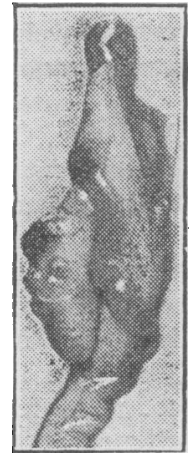

Fig. 2.-Ovary of 12-weeksold rabbit, which had been
injected with urine from a injected with urine from a
pregnant woman. Note projecting corpora haemorrhagica. $(x \mathbf{b}$.

injection the ovaries were inspected. Of the thirty-three cases twenty-eight were pregnant and five not pregnant, and in all cases the diagnosis was correct.

\section{COMMENTARY}

In the first series of twenty cases there was an error of 30 per cent. The failure in this series is, I believe, due to the fact that the rabbits were too young, as Snyder and Wislochi ${ }^{10}$ have shown that ovulation cannot be produced, even with concentrated urine, in rabbits aged less than 12 weeks. The rabbits used in this series were aged 10 to 12 weeks. In the second series the results are as good as those of the Zondek-Aschheim test.

An advantage of this test is the fact that rabbits are used ; these animals are readily obtained, while the five female mice, of specific age and weight, required for the Zondek-Aschheim test are not always available. Provided that the rabbit is not less than 12 weeks old, the age and weight are of no consequence. It is essential to be certain that ovulation has not taken place recently before the test is done, and that the rabbits are not pregnant. To ensure this, rabbits should be kept isolated for twenty days. It is also recommended that each rabbit should be isolated to avoid the possibility of pseudo-ovulation. Mortality among the rabbits has been a negligible factor. Morning specimens of urine were examined. Sterile precautions in injection of urine are not necessary.

\section{ConClusion}

The test is simple, rapid, and as reliable as the ZondekAschheim test.

\section{Reperences}

1 Aschheim, S.: Die Schwangerschaftsdiagnose aus dem Harne, Berlin, 1930.

2 Friedman, M. H.: Amer. Journ. Physiol., 1929, xc, 617.

3 Hammond, J., and Marshall, F. H. H.: Reproduction in the Rabbit, London, 1925.

- Brouha, Adèle: Compt. Rend. Soc. Biol., 1931, cvi, 61.

5 Idem: Personal communication to Dr. Herbert Spencer.

- Reinhart, H. L., and Scott, E.: Ainer. Journ. Clin. Path., 1931,

i, 113.
Schneider, P. F.: Surg., Gl'necol. and Obstet., 1931, lii, 56.

- Magath, T. B., and Randall, L. M.: Journ. Amer. Med. Assoc. 1931, xcvi, 1933

- Friedman, M. H., and Japham, M. E.: Amer. Journ. Obstet. and Gynecol., 1931, xxi, 405.

10 Snyder, F. F., and Wislochi, G. B.: Johns Hopkins Hosp. Bull., 331, xlix, 106.

\section{Memoranda}

\section{MEDICAL, SURGICAL, OBSTETRICAL}

\section{PRIMARY LARYNGEAL DIPHTHERIA}

Respiratory obstruction in a child may not be considered to be diphtheria in the absence of a membrane on the pharynx, and this may lead to the mere performance of a tracheotomy without the administration of diphtheria antitoxin. On one occasion I saw a child in extremis with respiratory obstruction on whom no diagnosis had been made, but on which a tracheotomy had been performed. The child died, and I have always wondered whether that child had laryngeal diphtheria. I think the following case is worth reporting, because I was able to see a membrane on the vocal cord on making a direct laryngeal examination, though no sign of a membrane was present in the pharynx.

An infant, aged $5 \frac{1}{2}$, was admitted to the hospital at 7 p.m. because of difficult respiration. The pharynx was normal in appearance. The house-surgeon considered that a tracheotomy was not then necessary, but informed me of the child's admission. At 10 p.m. I saw the child. At $\mathbf{9 . 4 5}$ a catheter had been inserted into the nostril and oxygen was administered continuously ; epigastric dipping and retraction of the intercostal spaces were present; the child was cyanosed and restless.

I injected novocain and made an incision. The haemorrhage was profuse, the child's pupils dilated fully, and breathing ceased. So I plunged the knife into the trachea and inserted a Jackson's tracheotomy tube. The child would not breathe and the pupils were still dilated, so I placed the tube from the $\mathrm{CO}_{2}$ cylinder in the tracheotomy tube and did artificial respiration. After some minutes breathing began. I then passed a Flagg's laryngoscope, and found the centre of the right vocal cord covered with a white membrane; the house-surgeon (Dr. E. D. F. Forster) injected 26,000 units of anti-diphtheria serum, and transferred the child to the fever hospital

In the fever hospital the medical officer of health for Darlington, Dr. G. A. Dawson, took charge of the child on the morning of July 12th, and he kindly sent me the following report:

On examination the temperature was $99.6^{\circ}$, pulse 142 , tonsils much enlarged and injected, no membrane or deposit visible. At 4 p.m. on July 12 th he was highly excited through respiratory distress; the tube was withdrawn, and a small piece of diphtheria membrane the size of a sixpence was removed by forceps, and 40,000 units of anti-diphtheritic serum was given intravenously. ... On July 14th at 7 a.m., after a fit of coughing, cyanosis became very marked, due to tracheal obstruction. Dr. Dawson was summoned, and removed the tube and introduced dilators moistened with a solution of 15 per cent. sodium carbonate. A tough membranous tracheal cast $3 \frac{1}{2}$ in. long by $1 / 2$ in. wide was removed by the use of forceps, giving immediate relief. The child made an uninterrupted recovery, and was discharged from hospital on August 20th. Dr. Dawson adds a note saying, "Every case of laryngeal obstruction of catarrhal origin should, in my opinion, be looked upon and treated as diphtheria, by the early intravenous administration of large doses of anti-diphtheritic serum."

Had the true nature of the condition been recognized antitoxin would have been given before the child was admitted to hospital, but, as it was, the condition was not recognized until three hours after admission. In tracheobronchial diphtheria the best treatment is a low tracheotomy, with repeated aspiration through a catheter attached to a suction machine such as all laryngologists now have. Such a machine should be kept in the patient's room, and should be used by the nurse. Bronchoscopy via the tracheal wound can easily herformed if necessary. 